\title{
Botulinum toxin type-A in the treatment of glabellar lines
}

\author{
This article was published in the following Dove Press journal: \\ Clinical, Cosmetic and Investigational Dermatology \\ 21 December 2009 \\ Number of times this article has been viewed
}

\author{
Leslie Winter ${ }^{\prime}$ \\ Jeffrey Spiegel ${ }^{2}$ \\ 'Department of Otolaryngology, \\ Boston Medical Center, Boston, MA, \\ USA $;{ }^{2}$ Chief, Division of Facial Plastic \\ Surgery Boston Medical Center \\ Boston, MA, USA
}

\begin{abstract}
The current literature and state of the art on use of botulinum toxin type-A in the treatment of glabellar rhytids was reviewed. Botulinum toxin type-A is a safe and effective way to manage glabellar rhytids. Mastery of the anatomy of the glabellar region, familiarity with the products currently available on the market and judicious dosing results in excellent cosmetic results with minimal adverse events.
\end{abstract}

Keywords: botulinum toxin, glabellar rhytids, cosmetic

\section{Background}

Since the early 1970 s, botulinum toxin type-A has been used for medical applications. In 2002 the US Food and Drug Administration (FDA) granted approval for cosmetic use of botulinum toxin type-A (BoTo-A) (Botox ${ }^{\circledR}$; Botox Cosmetic; Allergan, Irvine, CA, USA) in the treatment of glabellar rhytids. In 2009 the FDA approved the second BoTo-A (Dysport ${ }^{\circledR}$; Ipsen Limited, Berkshire, UK) for use in glabellar lines as well. The new availability of a similar, competing product reinforces the utility of a contemporary review of applications of botulinum toxin type-A in the glabellar brow region.

There are at least 7 subtypes of the neurotoxin produced by the bacterium Clostridium botulinum, but type-A is the most commonly used, and the only one currently approved for cosmetic use in the United States. Its selection as the primary therapeutic neurotoxin is due to early animal studies that demonstrated it was the most potent and longest lasting of all subtypes. ${ }^{1}$

BoTo-A naturally exists as a protein complex, for which an acidic environment is necessary for stabilization. Until it enters a neutral $\mathrm{pH}$ environment the active toxin moiety is not released. Its mechanism of action irreversibly blocks presynaptic release of acetylcholine at the neuromuscular junction. The average onset of clinically evident action is several days for both Botox and Dysport. This period of onset is related to the need for the process of endocytosis of the toxin into the cells of the nerve terminal with eventual disruption of the SNAP-25 protein that is responsible for release of acetylcholine into the neuromuscular junction. Paralysis therefore results from blockade of the conversion of an electrical signal from the nerves to the chemical signal at the neuromuscular junction. ${ }^{1}$

Recent reports of undesirable distant effects from BoTo-A which can resemble botulinum poisoning have surfaced. Symptoms reported include dysarthria, dysphagia, loss of bladder control, and difficulty breathing. ${ }^{2}$ It is important to note, however, that these small numbers of reported severe adverse events were in patients receiving very
Correspondence: Jeffrey Spiegel

Chief, Division of Facial Plastic Surgery,

Boston Medical Center, 830 Harrison

Avenue, Suite I400, Boston,

MA 02118 , USA

Tel +| 6|7-4|4-5058

Email jeffrey.spiegel@bmc.org
Clinical, Cosmetic and Investigational Dermatology 2010:3 I-4

(c) 2010Winter and Spiegel, publisher and licensee Dove Medical Press Ltd.This is an Open Access article which permits unrestricted noncommercial use, provided the original work is properly cited.

Dovepress 
large doses for conditions such as large muscle spasticity related to cerebral palsy and cervical dystonia. ${ }^{3}$ There have been no reports of distant complications related to cosmetic use of BoTo-A in the face.

\section{Preparation, storage and comparison}

Both Botox and Dysport require reconstitution with injectable saline. Botox is packaged in 100 Botox unit sterile vials. A single Botox unit is equivalent to the median lethal dose $\left(\mathrm{LD}_{50}\right)$ in mice when given intraperitoneally. Dysport is packaged in both 300 and 500 Dysport unit vials. Units between Botox and Dysport are not equivalent and it has been suggested that the ratio equivalents of Botox to Dysport range from 1:2.5 to $1: 5 .{ }^{4}$ Both manufacturers' recommend using preservativefree saline with gentle reconstitution utilizing the vacuum in the vial to draw in the saline. Aggressive injection of saline resulting in foaming could theoretically denature the neurotoxin protein complex. For Botox only, in our experience, a dilution of $4 \mathrm{~mL}$ of saline resulting in $2.5 \mathrm{U}$ per $0.1 \mathrm{~mL}$ injection results in highly reliable, effective and lasting results in the treatment of glabellar rhytids. The manufacturers for both Botox and Dysport recommend using the reconstituted product within four hours although Botox has been shown to be effective when preserved in a frozen state up to 6 months $s^{5}$ and in our experience for up to one month when refrigerated.

Initial reports with Dysport suggest that the while it is as efficacious and safe as Botox, the primary potential benefit is that a small subset of patients may have a very prolonged effect with normal dosage (eg, greater than 6 months). ${ }^{6}$ The main potential drawback is an increase in diffusion of Dysport owing to its smaller size (500 to $900 \mathrm{kDa}$ ) compared to Botox $(900 \mathrm{kDa}){ }^{4}$

\section{Use in glabellar rhytids}

While BoTo-A is used "off-label" (that is, for applications not specifically approved by the FDA) in many practices, including for treatment of facial rhytids around the eyes or from the frontalis muscle, the only approved cosmetic indication for either Botox or Dysport is in the treatment of glabellar rhytids. Carruthers and Carruthers ${ }^{7}$ noted that patients being treated with botulinum toxin for blepharospasm also had the added benefit of improved appearance. Several studies since have reproduced the safety and efficacy of BoTo-A for the treatment of glabellar rhytids.

Mastery of the anatomy of the glabellar complex is paramount for treatment of glabellar rhytids with BoTo-A. The complex is comprises the bilateral corrugator supercilii muscles. Activity of these muscles results in the formation of vertical rhytids along the brow. These often resemble a number " 11 " between the heads of the eyebrows. Additionally, the procerus muscle is active in the area. Firing of the procerus results in horizontal rhytids across the radix of the nose. Anatomical study has demonstrated that the thickest portion of the corrugator muscle is found consistently at the medial canthus, but with a significant amount of muscle bulk at the midpupillary line. The depth of the corrugator from the surface of the skin is constant from medial canthus to mid-pupil. There does not appear to be a vertical segment of the corrugator nor does there appear to be an anatomically distinct depressor supercilii as suggested by other authors as being a significant contributor. ${ }^{8,9}$

Appropriate therapeutic Botox dosing for treatment of the glabellar rhytids has been reported as anywhere from 20 to $50 \mathrm{U}$ over several injection sites. Dose-ranging studies for men and women in Botox have been performed and they suggest that $40 \mathrm{U}$ total over the area is effective in women and the minimum recommended starting dose for men. ${ }^{10,11}$ Our experience has been that approximately $95 \%$ of patients in our practice have good response and no serious complications using only $7.5 \mathrm{U}$ for each corrugator, $5 \mathrm{U}$ medially, $2.5 \mathrm{U}$ mid-pupil and $2.5 \mathrm{U}$ into the procerus. There is no need to inject the obicularis medially or laterally to successfully treat glabellar rhytids as suggested by other authors. ${ }^{\text {? }}$

Thus recommendations for injection (Botox) are as follows (Figure 1).

\section{Complications}

If you have an adverse aesthetic outcome in the use of BoTo-A, you can take solace in the knowledge that the effects are temporary. If the patient is pleased with the outcome, they must repeat injections to sustain an effect; however, if a patient experiences any complications they, too, are temporary. There are, however, a few more significant potential complications directly related to the injections that should be reviewed. The severe systemic effects as described in the FDA black box warning have not been reported in the cosmetic use of Botox or Dysport. The most common reported adverse side effect is eyelid ptosis.

Eyelid ptosis is caused by effects of the toxin on the upper eyelid levator muscle. This can occur if the toxin is directly injected into the muscle or close enough for the toxin to diffuse to the levator. Currently the recommendation is to not inject at or under the brow in the mid-pupil line, as this is the area of highest risk. Alpha-adrenergic eye drops (apraclonidine) can be used as a mydriatic agent 




\section{$x-5$ Botox Units \\ +-2.5 Botox Units}

Figure I Recommendations for injection (Botox).

if this complication occurs, and can provide temporary improvement in eyelid symmetry. The alpha-adrenergic medication causes contracture of Mueller's muscle, located just deep to the levator, and can thus improve the ptosis by a few millimeters. Allergan's FDA study for approval of cosmetic Botox reported eyelid ptosis at 5.4\%; however, this significantly drops once the physician's experience increases. ${ }^{12}$ With the above treatment regimen described our complication rate of eyelid ptosis is $0 \%$ over the past 10 years.

Minor complications such as pain, bruising and erythema are related to the needle necessary for injection and usually resolve within minutes to a few days (in the case of ecchymosis).

BoTo-A products should never be used in patients with neuromuscular junction disorders such as myasthenia gravis or Lambert-Eaton, and they are not recommended for pregnant women. ${ }^{13}$

Hypersensitivity or allergic reactions have not been reported, but resistance to the effect of Botox due to antibodymediated immunoresistance to the neurotoxin-protein complex has been described. Its prevalence is less than $5 \%$, however, and appears to be related to frequency of treatment, not duration of the regimen. ${ }^{14}$

\section{Conclusion}

BoTo-A has been proven to be a safe and effective means to treat glabellar rhytids. The new addition of Dysport as an alternative to Botox requires further experience in its application but early studies show promise that it is a viable alternative. The few feared systemic complications have been reported only when the toxin is used for large muscle disorders and in much higher doses than typically used for cosmetic indications. Serious complications such as eyelid ptosis can be avoided through judicious dosage selection and mastery of the underlying muscle anatomy.

\section{Disclosures}

The authors declare no conflicts of interest.

\section{References}

1. Rossetto O, Morbiato L, Caccin P, Rigoni M, Montecucco C. Presynaptic enzymatic neurotoxins. J Neurochem. 2006;97:1534-1545.

2. Kuehn B. Studies, Reports say botulinum toxins may have effects beyond injection site. JAMA. 2008;299:2261-2263. 
3. Kuehn B. FDA requires black box warnings on labeling for botulinum toxin products JAMA. 2009;301:2316.

4. Klein A, Carruthers A, Fagien S, Lowe NJ. Comparisons among botulinum toxins: an evidence-based review. Plastic Reconstr Surg. 2008; 121:413e.

5. Parsa AA, Lye KD, Don Parsa F. Reconstituted botulinum type-A neurotoxin: clinical efficacy after long-term freezing before use. Aesth Plast Surg. 2007;31:188-191.

6. Moy R, Maas C, Monheit G, Huber B. Long-term safety and efficacy of a new botulinum toxin type a in treating glabellar lines. Arch Facial Plast Surg. 2009;11:77-83.

7. Carruthers J, Carruthers A. Treatment of glabellar frown lines with C. botulinum. Dermatol Surg. 1992;18:17-21.

8. Macdonald MR, Spiegel JH, Raven RB, Kabaker SS, Maas CS. An anatomical approach to glabellar rhytids. Arch Otolaryngol Head Neck Surg. 1998;124:1315-1320.
9. Cook BE, Lucarelli MJ, Lemke BN. Depressor supercilii muscle: anatomy, histology, and cosmetic implications. Ophthal Plast Reconstr Surg. 2001;17:404-411.

10. Carruthers A, Carruthers J, Said S. Dose-ranging study of botulinum toxin type-A in the treatment of glabellar rhytids in females. Dermatol Surg. 2005;31:414-422.

11. Carruthers A, Carruthers J, Said S. Dose-ranging study of botulinum toxin type-A in the treatment of glabellar rhytids in males. Dermatol Surg. 2005;31:1297-1303.

12. Klein AW. Complications with the use of botulinum toxin. Dermatol Clin. 2004:22:197-205.

13. Carruthers A, Carruthers J. Cosmetic uses of botulinum A exotoxin. Adv Dermatol. 1997;12:325-347.

14. Klein A. Complications, adverse reactions, and insights with the use of botulinum toxin. Dermatol Surg. 2003;29:1146-1147.

\section{Publish your work in this journal}

Clinical, Cosmetic and Investigational Dermatology is an international, peer-reviewed, open access, online journal that focuses on the latest clinical and experimental research in all aspects of skin disease and cosmetic interventions. All areas of dermatology will be covered; contributions will be welcomed from all clinicians and basic science researchers globally. This journal is indexed on CAS. The manuscript management system is completely online and includes a very quick and fair peer-review system, which is all easy to use. Visit http://www.dovepress.com/testimonials.php to read real quotes from published authors. 